\title{
ENTES SIN PERSONALIDAD JURÍDICA COMO TITULARES DE EXPLOTACIONES AGRARIAS
}

\author{
Dra. Belén Trigo García \\ Profesora Contratada Doctor \\ Universidad Santiago de Compostela \\ Email: belen.trigo@usc.es
}

\begin{abstract}
RESUMEN: Una comunidad de bienes como arrendataria de un contrato de arrendamiento rústico, una comunidad de montes con capacidad de obrar, una explotación familiar agraria como socia de una cooperativa agraria... Estos supuestos, excepciones legales a la regla de que solo los entes con personalidad jurídica tienen capacidad de obrar, ¿son anomalías o una tendencia legal? ¿Importa todavía la personalidad jurídica? La presente contribución analiza la cuestión de si deben reconocerse legalmente, como expresa el título, entes sin personalidad jurídica como titulares de explotaciones agrarias con capacidad de obrar.
\end{abstract}

PALABRAS CLAVE: explotación familiar agraria, sociedad familiar agraria, comunidad de bienes, persona jurídica, capacidad de obrar

ABSTRACT: A community of property as a tenant of a rustic lease, a community of mountains with a capacity to act, a family farm as an agricultural cooperative partner... Are these cases, legal exceptions to the rule that only entities with legal personality have capacity to act, anomalies or a legal trend? Does it matter still legal personality? This contribution examines the question of whether they should be recognized legally, as it expresses the title, entities without legal personality as owners of farms with capacity to act

KEYWORDS: family farm, family-agrarian partnership, community of goods, legal person, capacity to act 


\section{Explotaciones agrarias familiares y forma jurídica}

Buena parte de las explotaciones agrarias en España tienen carácter familiar. Este carácter implica, en general, unas dimensiones reducidas y que tanto la titularidad de la actividad económica como el trabajo en la explotación correspondan a los miembros de un mismo grupo familiar ${ }^{1}$. La prevalencia de este modelo ${ }^{2}$ lleva a contemplar las comunidades familiares como sujeto agrario.

También los montes vecinales en mano común (mvmc) cumplen hoy un importante papel. De nuevo hablamos de comunidades, por tanto, sin personalidad jurídica. No obstante, es posible identificar en estos casos un patrimonio separado sometido a un régimen especial.

Una rápida revisión de la normativa estatal y autonómica aplicable tanto a las comunidades familiares agrarias como a las comunidades de montes muestra una situación que puede resultar, entonces, paradójica: comunidades de bienes, por tanto, patrimonios y grupos de personas sin personificar, que actúan -con reconocimiento legal- en el tráfico jurídico como sujetos distintos de las personas que las componen. En otras palabras, ¿cabe identificar partes de un contrato agrario o profesionales de la agricultura con capacidad de obrar pero sin capacidad jurídica en cuanto son entes sin personalidad?

\section{La capacidad de las comunidades de montes vecinales en mano común}

Las comunidades de montes vecinales en mano común están sometidas a un régimen de comunidad germánica en el que la propiedad se atribuye, sin asignación de cuotas, a los vecinos del área geográfica en que se ubica el monte. El origen consuetudinario de la

\footnotetext{
${ }^{1}$ Vid. entre otros, HERRERA CAMPOS, R., quien entiende que la explotación prioritaria debería ser familiar o asociativa, destacando como problemas la reducida dimensión de las explotaciones y la escasa cultura de empresa agraria, con la consiguiente necesidad de profesionalización ("Hacia un nuevo modelo de empresa agraria”, Estudios jurídicos de derecho agrario, E. MUÑIZ ESPADA, coord., Ministerio de Medio Ambiente y Medio Rural y Marino, Madrid, 2008, págs. 73-74).

${ }^{2}$ La preferencia por el ejercicio colectivo es una constante en el sector agrario si bien no resulta fácil encontrar una traducción jurídica técnica y precisa. Cfr. DE LOS MOZOS, J.L., "Formas jurídicas de la agricultura de grupo (sociedad, cooperativa y aparcería múltiple)", Estudios de derecho agrario, Tecnos, Madrid, 1972, pág. 237.
} 
figura explica que, pese al desarrollo legislativo actual, su regulación presente contornos difusos $^{3}$; afirmación aplicable al reconocimiento de su capacidad.

La Ley 52/1968, de 27 de julio, sobre montes vecinales en mano común (LMVMC 1968) entendía necesario otorgar personalidad jurídica a la comunidad vecinal propietaria del monte, al tiempo que establecía su estructura y organización. Así el art. 4.3 atribuía a la comunidad personalidad jurídica para el cumplimiento de sus fines, incluso el ejercicio en la vía judicial o administrativa de cuantas acciones fuesen precisas para la defensa de sus específicos intereses, correspondiendo la representación de la comunidad a la Junta respectiva.

Este planteamiento se mantuvo en la Ley estatal 55/1980, de 11 de noviembre, de Montes Vecinales en Mano Común (LMVMC), si bien con una diferencia terminológica. Ya no se habla de personalidad sino de capacidad. En concreto, según el art. 5.1, la administración, disfrute y disposición de los montes vecinales en mano común corresponden exclusivamente a la respectiva comunidad propietaria, que tendrá plena capacidad jurídica para el cumplimiento de sus fines.

También de capacidad jurídica habla el art. 4.1 de la Ley 13/1989, de 10 de octubre, de montes vecinales en mano común (LMVMCG) y el art. 20 párr. 3 Ley 7/2012, de 28 de junio, de montes de Galicia (LMG). De manera semejante, el art. 105.1 (Capacidad jurídica) Ley 3/2004, de 23 de noviembre, de montes de Asturias (LMA) prevé que la comunidad de vecinos propietaria de un monte vecinal en mano común tendrá plena capacidad jurídica para el cumplimiento de sus fines y la defensa de sus derechos, sobre el monte y sus aprovechamientos, así como sobre su administración y disposición.

Si bien la terminología empleada no resulta muy precisa, hay que entender que estas comunidades se configuran como un patrimonio separado; patrimonio al que se reconoce capacidad para actuar en el tráfico jurídico, por tanto, capacidad de obrar, aunque carece de personalidad o capacidad jurídica.

\footnotetext{
${ }^{3}$ En este sentido, la EM de la Ley 52/1968, de 27 de julio, sobre montes vecinales en mano común señalaba que, hasta ese momento, la situación legal en que se encontraban estos montes venía transcurriendo por vías de anormalidad, carentes de una regulación precisa.
} 
Un primer reconocimiento de esta capacidad de la comunidad de mvmc y su condición de propietaria se encuentra en la previsión legal de su inscripción registral a nombre de la respectiva comunidad titular ${ }^{4}$.

En materia de capacidad procesal, hay que entender incluidas las comunidades de mvmc en la referencia genérica a las entidades sin personalidad jurídica a las que la ley reconozca capacidad para ser parte recogida en los arts. 6.5 (Capacidad para ser parte) y 7.6 (Comparecencia en juicio y representación) LEC.

En cuanto a los concretos actos y negocios jurídicos que pueden celebrar las comunidades de mvmc como titulares del mismo, las leyes permiten la cesión total o parcial para obras, instalaciones, servicios o fines que redunden de modo principal en beneficio directo o principal de los vecinos ${ }^{5}$. También la celebración de contratos de arrendamiento $^{6}$ y de permuta ${ }^{7}$, y de convenios de explotación con la Administración Pública, entidades sociales, mancomunidades, cooperativas o particulares ${ }^{8}$, así como la constitución de derechos de superficie ${ }^{9}$.

Por su parte, el art. 57 (Adquisición de terrenos por las comunidades de montes vecinales en mano común) LMG establece a favor de las comunidades de mvmc un derecho de adquisición preferente tanto de las superficies colindantes como de sus enclavados. Este mismo precepto reconoce la capacidad de la comunidad para adquirir tierras- por donación (apartado 3) y, en general, se establece la plena capacidad jurídica (sic) para la realización de actos y negocios jurídicos vinculados a la adquisición de nuevos terrenos que redunden en beneficio de la comunidad vecinal (apartado 5).

\footnotetext{
${ }^{4}$ Vid. art. 5 LMVMC 1968, art. 13.1 y 3 LMVMC art. 13 a) y b) LMVMC; art. 110.2 LMA. Esta previsión suponía una excepción a la norma general contenida en la LH (vid. redacción originaria del art. 9.4). Con la nueva redacción del art. 9 apartado e) (Ley 13/2015, de 24 de junio), se admite la inscripción a favor, cuando sea el caso, del patrimonio separado cuando éste sea susceptible legalmente de ser titular de derechos u obligaciones.

5 Vid. art. 2 LMVMC1968, art. 3.1 LMVMC, art. 5 LMVMCG, art. 121 LMA. En general, sobre la facultad de disposición de la comunidad, vid. art. 5.2 LMVMC y art. 115.1 LMA.

${ }^{6}$ Vid. art. 5.5 LMVMC, art. 10 Decreto 260/1992, 4 de septiembre, por el que se aprueba el reglamento para la ejecución de la Ley 13/1989, de 10 de octubre, de montes vecinales en mano común (RMVMCG).

${ }^{7}$ Vid. art. 2.2 LOMVMC, art. 8 LMVMCG y art. 9 RMVMC.

${ }^{8}$ Vid art. 5.3 LMVMC, art. 25 y disposición adicional 2 LMVMCG, art. 123 LMG.

${ }^{9}$ Vid. art. 3.3-7 LMVMC, art. 7 LMVMCG y art. 8 RMVMCG, art. 123 LMA.
} 
Desde la perspectiva tributaria, estas comunidades están sometidas al impuesto de sociedades, hay que insistir, pese a no contar con personalidad jurídica (arts. 7.1.j) y 112 Ley 27/2014, de 27 de noviembre, del Impuesto sobre Sociedades).

Un posible límite a la capacidad de obrar de las comunidades de mvmc se encontraría en el hecho de que el reconocimiento de su capacidad se circunscribe al cumplimiento de los fines que le son propios. Claramente entre estos fines se encuentra la gestión, explotación, defensa, mejora y ampliación del monte, y el mejor aprovechamiento de los recursos ${ }^{10}$. El art. 57.3 LMG señala también como una justa motivación de la actuación de la comunidad el interés general de las personas comuneras (vid. infra epígrafe 3.1 y la condición de comunero de mvmc). Igualmente hay que tener en cuenta la función social que los montes como propiedad privada están llamados a cumplir (art. $33 \mathrm{CE})$.

Estos dos últimos aspectos permiten ampliar considerablemente el ámbito de actuación reconocido a las comunidades de mvmc. En efecto, cabe pensar en la actuación de la comunidad en beneficio no solo de los comuneros sino en general de los vecinos del área geográfica donde se encuentra el monte ${ }^{11}$. Al respecto, hay que tener en cuenta la contribución de los montes en la fijación de la población en el rural (vid. art. 119 LMG).

Igualmente conviene recordar que, sin perjuicio de que se mantengan los aprovechamientos tradicionales de los mvmc y su vocación agraria, tal calificación es independiente de sus posibilidades productivas y del tipo aprovechamiento ${ }^{12}$. Por tanto, la capacidad de actuación de la comunidad no se encuentra limitada a actividades forestales o agro-pecuarias ni por el actual aprovechamiento del monte ${ }^{13}$.

En conclusión, tanto la legislación civil, como la procesal y la tributaria consideran estas comunidades como titulares de la propiedad del monte, respecto del que pueden operar con una amplia capacidad.

\footnotetext{
${ }^{10}$ Vid. art. 123.1 y 8 a) LMG sobre cuotas de reinversión en montes vecinales en mano común.

${ }^{11}$ En este sentido, el art. 2 c) LMVMC 1968. Vid. también los arts. 21. 2 y 23 LMVMCG y el art. 125.8 b) y c) LMG.

${ }^{12}$ Vid. art. 102 LMA; art. 1 LMVMCG, art. 56 LDCG, art. 20 LMG. Expresamente se contempla el cambio de aprovechamiento (vid. art. 62.1 LMG).

${ }_{13}$ Vid. art. 3 a) Decreto 52/2014, de 16 de abril, por el que se regulan las instrucciones generales de ordenación y de gestión de montes de Galicia.
} 


\section{Explotaciones familiares agrarias sin personalidad jurídica}

Al considerar explotaciones familiares que no revisten la forma de persona jurídica parecería lógico entender que estamos ante un supuesto de titularidad a favor de una o más personas individuales ${ }^{14}$. Ahora bien, sin perjuicio de la titularidad formal de la explotación, la práctica suele revelar una realidad más compleja. En primer lugar, desde el punto de vista subjetivo es posible identificar un grupo de personas unidas por vínculos de parentesco que, sean o no propietarias de los elementos de la actividad económica, realizan una explotación conjunta. En segundo lugar, desde el punto de vista patrimonial, se trata de determinar si también en este caso podríamos estar ante un patrimonio separado. De modo que la combinación de ambos aspectos -subjetivo y patrimonial- podría justificar el reconocimiento a la comunidad como sujeto autónomo y diferenciado, con capacidad para actuar en el tráfico jurídico.

Para llegar a una conclusión es preciso hacer una revisión de las distintas hipótesis contempladas por las distintas legislaciones sectoriales, tanto de carácter estatal como autonómico.

3.1 La condición de comunero en la comunidad de mvmc como representante de una explotación familiar

Al examinar los requisitos para ser comunero en la comunidad de mvmc se comprueba que no todos los vecinos del área geográfica donde se encuentra situado el monte van a tener esta condición; en concreto, solo formarán la asamblea o junta general los representantes de las casas, en la denominación tradicional.

La expresión es recogida, literalmente, por el art. 7 LMVMC, según el cual, los Estatutos regularán quién ha de representar a cada «casa abierta con humos» en todo lo concerniente al monte, así como la forma de acreditar esa representación. En su defecto, la comunidad vecinal se entenderá válidamente con quien designen expresamente los miembros mayores de edad de cada familia o, si no lo hicieren, con quien asuma de hecho la dirección de la explotación familiar en cada casa.

\footnotetext{
${ }^{14}$ LUNA SERRANO, A., incluye en la empresa agraria individual a la conyugal y a la de base familiar, así como la que se asienta en una comunidad de bienes o en una comunidad hereditaria ("Panorama normativo del derecho agrario catalán (El régimen jurídico de la actividad agraria en Cataluña)", Derecho agrario autonómico, Santiago de Compostela, EGAP, 2003, pág. 377).
} 
En la legislación asturiana, el art. 104 (Comunidad privada) también atribuye la titularidad dominical del monte al conjunto de los vecinos titulares de unidades económicas, con «casa abierta con humos»o residencia habitual en las entidades de población a las que tradicionalmente hubiese estado adscrito su aprovechamiento. Serán los estatutos (art. 113 b) quienes regulen quién ha de representar a cada «casa abierta con humos» en todo lo concerniente al monte, así como la forma de acreditar esa representación, estableciendo, como norma subsidiaria, el mismo criterio que la ley estatal.

Muy similar es la regulación del art. 3.1 LMVMCG que se refiere como miembros de la comunidad al conjunto de los vecinos titulares de unidades económicas, con casa abierta y residencia habitual en las entidades de población a las que tradicionalmente hubiese estado adscrito su aprovechamiento, y que vengan ejerciendo, según los usos y costumbres de la Comunidad, alguna actividad relacionada con aquéllos. Y añade el art. 16.1 b) que los estatutos habrán de contener como mínimo, entre otros extremos, la representación por casa. De acuerdo con el artículo 39 RMVMCG, los miembros de cada «casa abierta» designarán de entre ellos quien ha de representarla en la asamblea general así como, en su caso, un suplente. En su defecto lo hará quien asuma de hecho la dirección de la explotación familiar. La actual Ley 2/2006, de 14 de junio, de derecho civil de Galicia (LDCG), por su parte, se refiere a personas titulares de unidades económicas, productivas o de consumo (art. 61.2). A los efectos aquí considerados y sin perjuicio de los matices de diferencia, cabe entender que la realidad descrita es la misma: representante de un grupo familiar y de una unidad económica ${ }^{15}$.

Por tanto, la legislación en materia de montes reconoce a las unidades económicas familiares como titulares de la propiedad del mvmc con la condición de comuneros.

\footnotetext{
15 Sobre la referencia a unidad económica para definir la explotación agraria, vid R. HERRERA CAMPOS, R., loc. cit., pág. 67. Sobre la sobre la condición subjetiva de vecino comunero, vid. BUSTO LAGO , J. M. (dtor), ÁlVAREZ LATA, N., PEÑA LÓPEZ, F., Curso de Derecho civil de Galicia, Atelier, Barcelona, 2015, págs. 239-240. En opinión de FERNÁNDEZ SANTIAGO, C., entre las unidades económicas podrían incluirse la unidad económica y patrimonial derivada de la sociedad de gananciales o de la familiar ("Comentario al art. 61", en Comentarios a la Ley de Derecho civil de Galicia, Ley 2/2006, de 14 de junio, A. L. REBOLLEDO VARELA (coord.), Thomson-Aranzadi, Cizur Menor (Navarra) 2008, págs. 326-329).
} 


\subsection{Las comunidades de bienes como arrendatarias rústicas}

La Ley 49/2003, de 26 de noviembre, de Arrendamientos Rústicos (LAR), equipara las comunidades de bienes a las personas jurídicas a efectos de la capacidad para celebrar un contrato de arrendamiento rústico como arrendataria. Así, el art. 9.2 dispone que, en todo caso, podrán ser arrendatarias las cooperativas agrarias, las cooperativas de explotación comunitaria de la tierra, las sociedades agrarias de transformación y las comunidades de bienes [vid. en el mismo sentido, el art. 24 f) (Terminación del arrendamiento)].

La EM IV de la LAR señalaba como una importante novedad el permitir celebrar el contrato a las comunidades de bienes, a las que califica como "una forma asociativa crecientemente utilizada" 16 .

Cabe preguntarse por qué no se dice nada de su capacidad para ser arrendadoras. De hecho, la interpretación literal de los apartados 1 (podrán celebrarse arrendamientos rústicos entre personas físicas o jurídicas) y 2 del art. 9 LAR daría lugar a la conclusión de que solo podrían celebrar el contrato como arrendatarias.

Tampoco resulta claro que, a partir de lo establecido en esta ley, las comunidades de bienes arrendatarias rústicas puedan ser consideradas profesionales de la agricultura ${ }^{17}$, pese a su equiparación a sociedades de naturaleza agraria.

Igualmente resulta dudosa, aunque en un sentido diverso, la regulación catalana sobre contratos de cultivos. Así, el art. 623-5.1 (Partes contractuales) Ley 3/2017, de 15 de febrero, del libro sexto del Código civil de Cataluña permite que puedan establecer contratos de cultivo las personas con capacidad para contratar. Por su parte, el art. 623-6 define en su apartado 1 cultivador directo y personal como la persona física que, sola o

\footnotetext{
${ }^{16}$ Esta previsión ha sido criticada por parte de la doctrina. En este sentido, GUILARTE MARTÍNCALERO, C., opina que es un despropósito que sea la comunidad y no los comuneros la titular del arrendamiento por carecer la comunidad de bienes de personalidad jurídica; por tanto, la titularidad la ostentarán los comuneros que contratan para la comunidad ("Comentarios al art. 9 y al art. 24. F", en Comentarios prácticos a la nueva Ley de arrendamientos rústicos, Lex Nova, Valladolid, 2004, págs. 212-213 y pág. 428 , respectivamente). Ahora bien, de aceptarse, abre un interesante campo de debate; así, por ejemplo, en virtud del art. 9 LAR podría defenderse el reconocimiento de cierta proyección exterior de la explotación resultante del contrato de aparcería asociativa, aun cuando no se le reconozca personalidad jurídica (vid. TRIGO GARCÍA, B., "Comentario al art. 32", en Comentarios prácticos a la nueva Ley de arrendamientos rústicos, cit., pág. 603).

${ }^{17}$ Vid. art. 9.1 párr. 2 LAR, que define el agricultor profesional en referencia a la persona física individual.
} 
con la colaboración de personas que conviven con ella o, si no existe convivencia, de descendientes o de ascendientes, lleva a cabo efectivamente la actividad agraria y asume los riesgos de la explotación; y el apartado 2 atribuye la condición la condición de cultivador directo y personal a las sociedades de carácter agrario a las que equipara las sociedades las comunidades de bienes. Entonces, ¿por qué no se reconoce a las comunidades como sujeto con capacidad para celebrar contratos de cultivo?

La diferencia entre comunidad y sociedad se difumina también en la ley estatal a propósito de la regulación de la aparcería (vid. art. 32 LAR) que, según recuerda la EM LAR, al margen de su vigencia tradicional, revive en figuras nuevas de contratos agroindustriales o de integración ${ }^{18}$.

\subsection{La cotitularidad de las explotaciones agrarias}

La Ley 35/2011, de 4 de octubre, sobre titularidad compartida de las explotaciones agrarias, introduce con efectos no solo administrativos (vid. Real Decreto 297/2009, de 6 de marzo, sobre titularidad compartida en las explotaciones agrarias), sino también civiles, una nueva figura jurídica que busca visibilizar a la mujer y promover el reconocimiento jurídico y económico de su participación en la actividad agraria (vid. art. 1.1 ${ }^{19}$. Como justificación de su necesidad, la EM alude a la situación fáctica en el que más del 70\% de los titulares de explotaciones agrarias en España son hombres cuando "En el ámbito de la explotación familiar del medio rural, son muchas las mujeres que comparten con los hombres las tareas agrarias, asumiendo buena parte de las mismas y aportando tanto bienes como trabajo. Sin embargo, en la mayoría de los casos, figura sólo el hombre como titular de la explotación agraria, lo que dificulta que se valore adecuadamente la participación de la mujer en los derechos y obligaciones derivados de la gestión de dicha explotación, en condiciones de igualdad"20.

\footnotetext{
18 Sobre aparcería y contratos de integración vid. TRIGO GARCÍA, B., "Comentario al art. 32", en Comentarios prácticos a la nueva Ley de arrendamientos rústicos, cit., págs. 599-601.

${ }^{19}$ Vid. ESPÍN ALBA, I, "La titularidad compartida de las explotaciones agrarias. Perspectivas a partir del Real Decreto 297/2009, de 6 de marzo", en LÓPEZ DE LA CRUZ, L. Y OTERO CRESPO, M. (Coords.), El levantamiento del velo: Las mujeres en el derecho privado, Edit. Tirant lo Blanch, Valencia, 2011, págs. 1343-1366, y NAVAS NAVARRO, S., "Uso y tenencia de bienes por las mujeres. Aplicación de las "acciones positivas" en el Derecho privado", ibídem, pág. 1319.

${ }^{20}$ Vid. DUEÑAS HERRERO, L. J., y SERRANO ARGÜELLO, N., "El trabajo de la mujer en el mundo agrario. Ayer y hoy de las leyes sociales", y RICO GONZÁLEZ, M., "La mujer y su relevancia en el proceso de desarrollo agrario español", en Estudios jurídicos de derecho agrario, cit., págs. 507 y ss., y págs. 583 y ss., respectivamente.
} 
Por tanto, se piensa explotaciones familiares y comunitarias en cuanto existe una participación activa (trabajo directo y personal ex art. 3 con remisión a la LMEA) de distintos miembros de la familia, pero con un titular único.

La titularidad compartida se presenta como una estructura agraria, relacionada con el régimen personal, sin afectar a la organización de la propiedad de los elementos de la explotación. Se concibe así como como unidad económica, sin personalidad jurídica, y susceptible de imposición a efectos fiscales ${ }^{21}$, que constituye un matrimonio o pareja de hecho, para la gestión conjunta de la explotación agraria (vid. art. 4. Administración, representación y responsabilidad de la explotación agraria de titularidad compartida) y diferenciando entre la titularidad de la explotación ${ }^{22}$ y la titularidad dominical de los bienes y sus derechos, cuyo régimen jurídico civil no se ve afectado (art. 2).

No se califica jurídicamente la naturaleza de la figura -unidad económica es un concepto de carácter económico, que puede revestir múltiples formas jurídicas. En todo caso, la ley se cuida de calificarla de comunidad de bienes, aunque podría encajar en esta hipótesis, bien de forma inicial, bien de forma sobrevenida. Sí parece excluir su carácter societario. En este sentido (disposición adicional primera), se prevé como una vía de acceso a la administración conjunta de la explotación agraria, diferente de la titularidad compartida y sin que le resulte de aplicación su régimen jurídico, la constitución de una sociedad de responsabilidad limitada.

Estas explotaciones gozan de publicidad mediante su inscripción en el Registro de titularidad compartida que tiene carácter constitutivo (arts. 6 y 7). En este sentido, el reconocimiento y las ventajas de que gozan estas explotaciones están supeditados a esta inscripción registral.

Pese a estas circunstancias (contar con un número de identificación fiscal, exigirse inscripción registral) que configuran un patrimonio separado, resulta dudoso que se reconozca a estas explotaciones capacidad de obrar. Por ejemplo, a efectos de abrir una

\footnotetext{
${ }^{21}$ De acuerdo con el art. 9 (Régimen fiscal de la titularidad compartida), la titularidad compartida de explotaciones agrarias tendrá la consideración a efectos tributarios de entidad del artículo 35.4 de la Ley 58/2003, de 17 de diciembre, General Tributaria, por lo que tendrá un número de identificación fiscal para sus relaciones de naturaleza o con trascendencia tributaria.

${ }^{22} \mathrm{Al}$ respecto, el art. 5 prevé un reparto al 50\% de los rendimientos, a los que, una vez repartidos les será de aplicación el régimen económico correspondiente aplicable a los cónyuges o miembros de la unión no matrimonial titulares de la explotación agraria de titularidad compartida.
} 
cuenta bancaria asociada a la titularidad compartida (cfr. art. 6.2 e) a nombre de la explotación. En este sentido, el art. 11 habla de ayudas agrarias "asociadas a la explotación agraria de titularidad compartida" cuyos beneficiarios serán las personas titulares de la explotación, no la unidad económica.

\subsection{Las sociedades familiares agrarias}

Desde una perspectiva diferente a la de la cotitularidad ${ }^{23}$, aunque también con el objetivo de incentivar las explotaciones agrarias y el mundo rural, la Ley 49/1981, de 24 de diciembre, del Estatuto de la explotación familiar agraria y de los agricultores jóvenes, reconocía un patrimonio -la explotación familiar (vid. art. 3 sobre elementos de la explotación)- con un régimen propio, así, a propósito de la transmisión inter vivos y mortis causa, con el objeto de mantener la integridad de la explotación agraria como unidad empresarial (vid. art. 1 Objeto y fines) ${ }^{24}$.

Para acceder a este régimen especial se requería un reconocimiento formal; en concreto, un documento administrativo, expedido por el Ministerio de Agricultura, que acreditaba el carácter de explotación familiar en el que se describían los bienes y derechos de la explotación (vid. art. 10). Por otra parte, la regulación del trabajo familiar a través de pactos con los colaboradores (art. 5), aproximaba esta figura al contrato de sociedad, si bien en un contexto familiar.

En la actualidad, el Decreto Legislativo 1/2011, de 22 de marzo, del Gobierno de Aragón, por el que se aprueba, con el título de «Código del Derecho Foral de Aragón», el Texto Refundido de las Leyes civiles aragonesa, incluye algunas referencias a comunidades familiares en relación con la costumbre (vid. art. 201 sobre instituciones familiares consuetudinarias como el casamiento para casa o el consorcio universal o

\footnotetext{
${ }^{23}$ En cuanto al elemento subjetivo, la ley de explotaciones familiares agrarias contemplaba una titularidad individual, acorde con el modelo tradicional de familia jerarquizada; en este sentido, el art. 2 exigía que los trabajos en la explotación fuesen realizados personalmente por el titular, que debía desarrollar la actividad empresarial agraria como principal, y su familia, sin que la aportación de mano de obra asalariada fija, en su caso, superase en cómputo anual a la familiar en jornadas efectivas (vid. art. 5 sobre colaborador de la explotación familiar agraria). La preferencia por un titular único es clara en el Decreto 118/1973, de 12 de enero, por el que se aprueba el texto de la Ley de Reforma y Desarrollo Agrario al regular los patrimonios familiares (vid. art. 36.2).

24 LUNA SERRANO, A., explica el fracaso de esta ley, entre otras razones, por sus numerosas deficiencias técnicas; también la pone como ejemplo de lo complejo que resulta en la práctica traducir legislativamente la opción del legislador por la empresa agraria familiar ("Panorama normativo del derecho agrario catalán (El régimen jurídico de la actividad agraria en Cataluña)”, cit., pág. 377).
} 
juntar dos casas), y el régimen económico y sucesorio familiar (vid. arts. 202, 381 y 461 sobre sucesión de la casa).

La Ley 5/2015, de 25 de junio, de Derecho Civil Vasco, también contempla un cierto reconocimiento del patrimonio familiar con base en su tradición. Respecto de los principios de solidaridad y función social del derecho patrimonial, el art. 5.1, hace referencia a la propiedad familiar, diferenciándola de la propiedad individual. En este sentido, el art. 107, respecto del pacto de comunidad, habla de comunidad o sociedad familiar. Hay que tener en cuenta que se prevé que formas tradicionales de asociación revistan la forma de sociedad civil que, una vez inscritas en un registro especial al efecto, adquirirían personalidad jurídica (art. 16). Cabría pensar, entonces, en la aplicabilidad de esta disposición a las sociedades familiares derivadas de un pacto de comunidad, por ejemplo, para la sucesión de la explotación familiar agraria (vid. arts. 12 y 97 sobre la definición de caserío).

En el ámbito del derecho gallego, hay un cierto reconocimiento de la capacidad de obrar de la sociedad familiar ${ }^{25}$ conocida como compañía familiar gallega. Esta figura se define en el art. 157 LDCG como la constituida entre labradores con vínculos de parentesco, para vivir juntos y explotar en común tierras, lugar $\operatorname{acasarado}^{26} \mathrm{o}$ explotaciones pecuarias de cualquier naturaleza pertenecientes a todos o a alguno de los reunidos.

\footnotetext{
${ }^{25}$ La naturaleza de la figura como comunidad de bienes o sociedad, que es la opción aquí defendida, es discutida (vid. BUSTO LAGO, J. M. (dtor), ÁlVAREZ LATA, N., PEÑA LÓPEZ, F., Curso de Derecho civil de Galicia, cit., págs. 145-148); así, FERNÁNDEZ SANTIAGO, C. la caracteriza de institución ambivalente, si bien recoge su relación con las sociedades tácitas agrícolas ("Comentario al art. 157”, Comentarios a la Ley de Derecho civil de Galicia, cit., págs. 669). Por su parte, el art. 47 Ley 147/1963, de 2 de diciembre, sobre compilación del derecho civil especial de Galicia, disponía, con carácter supletorio, la aplicación de las reglas relativas a la sociedad civil, respecto de compañía familiar agraria.

${ }^{26}$ Se entiende por lugar acasarado (art. 119 LDCG) el conjunto formado por la casa de labor, edificaciones, dependencias y fincas, aunque no sean colindantes, así como toda clase de ganado, maquinaria, aperos de labranza e instalaciones que constituyan una unidad orgánica de explotación agropecuaria, forestal o mixta. Vid. TRIGO GARCÍA, B., "La noción de lugar acasarado en la Ley de Derecho civil de Galicia. Espacial referencia al arrendamiento de lugar acasarado", AC, n 28 1999, págs. 797 y ss.
} 
Será el representante de la compañía familiar gallega y de la casa ${ }^{27}$ - en la terminología tradicional, el patrucio - quién forme parte de la veciña (vid. arts. 52-53 y LDCG), como también se vio respecto de la asamblea general de los $\mathrm{mvmc}^{28}$.

Por su parte, la Ley 5/1998, de 18 de diciembre, de Cooperativas de Galicia (LCG), posibilita la incorporación como socio de la compañía familiar gallega, configurada como unidad económica única, en la cooperativa agraria. Se exige que la compañía esté constituida formalmente y debidamente documentada ${ }^{29}$ para tener la consideración de persona socia única (vid. art. 111.2), sin perjuicio de que los estatutos puedan establecer, con carácter general, la forma en que los miembros de la comunidad familiar vinculados a la explotación agraria de la persona socia, o quienes con ella convivan, puedan beneficiarse de las actividades y servicios que la cooperativa desarrolle o preste.

También la Ley 10/1985, de 14 de agosto, de Concentración Parcelaria para Galicia (LCPG), ahora derogada, tomaba en consideración la compañía familiar gallega (art. 5 bis) para determinar la dimensión económicamente viable de una zona. Asimismo, se preveía elaborar una relación de compañías familiares gallegas afectadas por la concentración (vid. arts. 21-22).

Como se ve, tanto la LCG como la LCPG se mostraban respetuosas con figuras tradicionales reguladas en la legislación civil. Expresamente, el Preámbulo LCPG explicaba que una ley de sus características había de tener en cuenta el hecho diferencial del país donde va a actuar y teñirse con las experiencias culturales y jurídicas básicas que tienen una tradición consuetudinaria. Justificaba así que la compañía familiar gallega quedase legitimada para que poder ser titular de todos los derechos $\mathrm{y}$ obligaciones que la iniciación y prosecución de la concentración llevan consigo.

\footnotetext{
${ }^{27}$ La compañía familiar gallega es una institución al servicio de la Casa (vid. BUSTO LAGO, J. M., "Comentario al art. 51", Comentarios a la Ley de Derecho civil de Galicia, cit., págs. 287-288) relacionada con el régimen económico familiar y sucesorio (vid. arts. 174 sobre capitulaciones matrimoniales y 219 sobre la mejora de labrar y poseer LDCG).

${ }^{28}$ Sobre la relación entre mvmc y veciña, la figura de patrucio y de comunero, vid. TRIGO GARCÍA, B., "Las comunidades de bienes en el derecho gallego. Bienes en mano común: normas administrativas y su vinculación con la casa. La competencia del legislador gallego en materia de comunidad de aguas y conexión registral", AC, n 30, 2001, págs. 1062- 1069; BUSTO LAGO, J. M., "Comentario al art. 52", Comentarios a la Ley de Derecho civil de Galicia, cit., págs. 293 y ss. BUSTO LAGO, J. M. (dtor), ÁLVAREZ LATA, N., PEÑA LÓPEZ, F., Curso de Derecho civil de Galicia, cit., págs. 226 y ss.

${ }^{29}$ Se admite la constitución tácita de la compañía familiar gallega (vid. art. 160 sobre casar para casa y art. 163 LDCG).
} 
En cambio, las recientes leyes gallegas en materia de estructura agraria omiten toda referencia a la compañía familiar gallega, si bien se encuentra alguna referencia a patrimonios separados no personificados ${ }^{30}$.

Para poner fin a esta revisión, no exhaustiva, ha de tenerse en cuenta la regulación navarra que, si bien con un carácter muy tradicional, hace un reconocimiento expreso de la capacidad de obrar de la comunidad familiar de carácter agrario pese a la falta de personificación.

Ya el Preámbulo de la Ley 1/1973 de 1 de marzo, por la que se aprueba la Compilación del Derecho Civil Foral de Navarra, hacía referencia a la "realidad desatendida por la legislación, pero de insoslayable vigencia, cual es los sujetos colectivos sin personalidad jurídica". En concreto, a los efectos que aquí interesan, la ley 48 dispone que la casa, sin constituir persona jurídica, tiene su propio nombre y es sujeto de derechos $\mathrm{y}$ obligaciones respecto a las relaciones de vecindad, prestaciones de servicios, aprovechamientos comunales, identificación y deslinde de fincas y otras relaciones establecidas por la costumbre y usos locales; correspondiendo a los amos (sic) el gobierno de la casa, el mantenimiento de su unidad y la conservación y defensa de su patrimonio y nombre. Al respecto, el régimen de los bienes familiares ha de atender a la unidad de la casa y la conservación de la explotación agraria (ley 75) y se regula la disolución de las comunidades familiares, distinguiendo dos situaciones; en primer lugar (ley 128), las comunidades constituidas formalmente, es decir, cuando existe un título de constitución; en segundo lugar (ley 129), las comunidades de hecho, derivadas de situaciones de convivencia y colaboración.

En mi opinión, estos preceptos tomados en su conjunto, podrían dar pie a la regulación de una sociedad familiar agraria, más allá de la figura de la comunidad de bienes ${ }^{31}$, y

\footnotetext{
${ }^{30}$ La Ley 4/2015, de 17 de junio, de mejora de la estructura territorial agraria de Galicia, exige en general personalidad jurídica (vid. art. 4.13 sobre iniciativas agrarias de aprovechamiento en común o el art. 45). A efectos de responsabilidad por infracciones, el art. 95.3 contempla los partícipes de las comunidades sin personalidad jurídica como unidades económicas o patrimonios separados, susceptibles de imposición. La misma referencia se encuentra en el art. 43.3 Ley 6/2011, de 13 de octubre, de movilidad de tierras también a efectos de responsabilidad por infracciones; esta misma ley, en su art. 3.5 incluye en la definición de persona titular de la explotación a la agrupación de personas físicas o jurídicas o las entidades asociativas sin personalidad jurídica propia.

${ }^{31}$ Es un tema ampliamente discutido en la doctrina la distinción entre sociedad y comunidad de bienes, distinción que se torna más borrosa en la actualidad por la mayor necesidad de colaboración entre comuneros, el incremento de las relaciones de la comunidad con terceros y la creciente formalización. El elemento tradicional de la affectio societatis (animus contrahendis societatis) resulta excesivamente
} 
que podría estar dotada de personalidad jurídica como sociedad civil ${ }^{32}$; en todo caso, susceptible de que se le reconozca capacidad de obrar al margen de su personificación.

\section{Conclusiones}

Del análisis de los supuestos legales cabe concluir que no estamos ante excepciones puntuales al principio de que solo los entes con personalidad jurídica pueden contratar en el sector agrario, actuar con eficacia en el tráfico jurídico y ser titulares de los derechos y obligaciones derivados de tal actuación.

En efecto, de una parte, cabe considerar estos casos como patrimonios separados; de otra, resulta posible identificar las personas que integran en estos entes en cada momento, para lo que bastaría una constitución formal y no meramente tácita como medio de superar los problemas de prueba que pudieran surgir en la práctica.

Desde esta perspectiva importa más el concreto régimen jurídico aplicable a la figura comunidad de mvmc, comunidad de bienes, sociedad familiar- que el reconocimiento o no de personalidad jurídica.

Obviamente, resultaría conveniente que la aceptación de esta postura estuviera acompañada de una reflexión general sobre el papel de la personalidad jurídica en el ordenamiento español. En todo caso, permitiría dar respuesta a la preocupación legal por apoyar las explotaciones familiares agrarias y solucionar el problema de su encaje jurídico, vistas las críticas y el escaso éxito de las iniciativas legislativas hasta el momento planteadas.

En especial, permitiría dar seguridad jurídica a estas explotaciones agrarias y a quienes contratan con ellas; también a las personas que las integran en cuanto a sus derechos y obligaciones cuando su participación constituya algo más que una mera colaboración informal y puntual. Esta es una cuestión central vistas las contradicciones, lagunas,

ambiguo como criterio de distinción. Por lo que respecta a la personalidad jurídica, caben sociedades civiles sin personalidad $e x$ art. 1669 CC. En particular respecto de las sociedades familiares, J. CASTÁN TOBEÑAS justificada las reservas a la equiparación de la compañía familiar al contrato de sociedad precisamente por el elemento familiar (Derecho civil español, común y foral. Derecho de obligaciones: las particulares relaciones obligatorias, t. IV, 12 ed. Reus, Madrid, 1985, pág. 633). Ciertamente, el carácter familiar podrá justificar particularidades en su régimen jurídico, pero no se alcanza a entender por qué un patrimonio familiar no habría de gestionarse con criterios empresariales y revestir una forma societaria.

${ }^{32}$ Sobre el tema, vis. I. A. CALVO VIDAL, La persona jurídica societaria, Consejo General del Notariado, 2011, págs. 195 y ss., y la abundante bibliografía allí citada. 
dudas y ambigüedades que, como se ha señalado, se advierten en la regulación actual, tanto estatal como autonómica. 


\section{BIBLIOGRAFÍA}

- Busto lago, J. M. (dtor), Álvarez lata, N., PEÑA LÓPEZ, F., Curso de Derecho civil de Galicia, Atelier, Barcelona, 2015

- CALVO VIDAL, La persona jurídica societaria, Consejo General del Notariado, 2011

- DE LOS MOZOS, J.L., "Formas jurídicas de la agricultura de grupo (sociedad, cooperativa y aparcería múltiple)", Estudios de derecho agrario, Tecnos, Madrid, 1972

- DUEÑAS HERRERO, L. J., y SERRANO ARGÜELLO, N., "El trabajo de la mujer en el mundo agrario. Ayer y hoy de las leyes sociales", y RICO GONZÁLEZ, M., "La mujer y su relevancia en el proceso de desarrollo agrario español", en Estudios jurídicos de derecho agrario, 2015

- ESPÍN ALBA, I, "La titularidad compartida de las explotaciones agrarias. Perspectivas a partir del Real Decreto 297/2009, de 6 de marzo", en LÓPEZ DE LA CRUZ, L. Y OTERO CRESPO, M. (Coords.), El levantamiento del velo: Las mujeres en el derecho privado, Edit. Tirant lo Blanch, Valencia, 2011

- FERnÁndez SANTIAGO, C.: "Comentario al art. 61", en Comentarios a la Ley de Derecho civil de Galicia, Ley 2/2006, de 14 de junio, A. L. REBOLLEDO VARELA (coord.), Thomson-Aranzadi, Cizur Menor (Navarra) 2008

- GUilarte MARTín-CALERO, C.: “Comentarios al art. 9 y al art. 24. F”, en Comentarios prácticos a la nueva Ley de arrendamientos rústicos, Lex Nova, Valladolid, 2004

- HERRERA CAMPOS, R.: "Hacia un nuevo modelo de empresa agraria", Estudios jurídicos de derecho agrario, E. MUÑIZ ESPADA, coord., Ministerio de Medio Ambiente y Medio Rural y Marino, Madrid, 2008

- LUNA SERRANO, A.: "Panorama normativo del derecho agrario catalán (El régimen jurídico de la actividad agraria en Cataluña)", Derecho agrario autonómico, Santiago de Compostela, EGAP, 2003 